\title{
Hand Hygiene Knowledge, Attitude and Practices among Postgraduates and CRRIs in a Tertiary Care Hospital, Chennai, India
}

\author{
B. Ravichandran ${ }^{1}$, K.V. Leela ${ }^{2 *}$, Thyagarajan Ravinder ${ }^{3}$, M. Kavitha ${ }^{4}$, \\ S. Hemalatha ${ }^{5}$ and C. Rajasekaran ${ }^{6}$ \\ Department of Microbiology, Govt. Kilpauk Medical College \& Hospital, Chennai, India \\ *Corresponding author
}

\section{A B S T R A C T}

\section{Keywords}

Hand hygiene, Hospital acquired infections, Postgraduates, CRRIs, KAPS

Article Info

Accepted:

10 December 2018 Available Online:

10 January 2019
The importance of hands in the transmission of hospital infections has been well demonstrated and hand hygiene reduces the prevalence of hospital acquired infections. The study was designed to evaluate the knowledge, attitude, practices and satisfaction of the available facilities among Postgraduates and CRRIs and to identify the gaps in hand hygiene practices and to implement an Institutional program on hand hygiene policy. A self-administered questionnaire was used. The study was conducted between September 2018 and November 2018. A total of 275 participants (148 Postgraduates and 127 CRRIs) participated in the study. Data was analyzed using Microsoft excel 2010 software. Pearson chi-square test was used to check for statistically significant differences. A p-value of less than 0.05 was considered significant. Majority had moderate knowledge $(90.9 \%)$ whereas postgraduates had better knowledge than CRRIs. The study population had moderate attitude $(40.7 \%)$ and practices (44\%). Postgraduates had good attitude and practices than the CRRIs. $73.5 \%$ suggested improvement of the available facilities. A need for hand hygiene training program and multifaceted interventional behavioral program particularly for the medical students to improve the compliance.

\section{Introduction}

HAI is defined as infection occurring in a patient during the process of care in a healthcare facility which was not present or incubating at the time of admission (1). In tertiary care settings, patients come in contact with a wide range of healthcare professionals including medical students and the poor adherence to Infection Control Measures (ICMs) contributes to HAIs (2). The importance of hands in the transmission of hospital infections has been well demonstrated (3). The prevalence of HAIs can be reduced by effective hand hygiene but the compliance to it among health care professionals, is as low as $40 \%$ (4).

Factors contributing to this lack of compliance are due to inadequate knowledge and lack of awareness on hand hygiene, poor attitude, over workload with understaffing, lack of time, skin irritation, and inadequate facilities. Based on the guidelines published by WHO 
on hand hygiene, regular training programs and surveys to be carried out to assess the hand hygiene practices among the health care professionals (5).

This study is carried out with the aim of assessing the knowledge, attitudes, practices and satisfaction of facilities available to Postgraduates and CRRIs with regard to hand hygiene. The objectives of this study are to identify the gaps in hand hygiene practices and to draft an Institutional program on hand hygiene policy.

\section{Materials and Methods}

\section{Setting}

The study was conducted between September 2018 and November 2018 in a Medical College \& Hospital, Chennai, India that provides a range of specialized health care.

\section{Study population}

Postgraduates (PG) and Compulsory rotatory resident internship (CRRIs) were participated in the study. The investigator visited them and explained the nature of study. Written consent was obtained from those who volunteered to participate in the study and confidentiality was ensured throughout the study

\section{Study design}

This was a questionnaire based cross sectional descriptive study. Ethical clearance for the study was obtained from institutional ethics committee.

A self-administered questionnaire was used which consists of five parts such as demographic information, assessment of knowledge, attitude, practices and availability of facilities. Knowledge was assessed by 25 questions which include multiple choice and yes or no and true or false questions. Attitudes were measured using 10 questions where the participants were given the option to select on a 1 to 7 point scale. Scale between strongly agree to strongly disagree. Practices and facilities were assessed in similar way using 6 and 8 questions respectively. The first two responses are taken as positive response and the rest taken as negative response.

A scoring system was used where 1 point was offered for each correct response to knowledge, attitude, practices and facilities. 0 point was given for incorrect response. A score of more than $75 \%$ was considered good, $50-74 \%$ was considered as moderate, and less than $50 \%$ was considered as poor. In our study we used descriptive statistics by use of percentages for each of the responses given. The cut off values to determine good, moderate and poor levels were taken from previously published studies with some modification to suit our purpose (6).

\section{Data analysis}

Data was analyzed using Microsoft excel 2010 software. Pearson chi-square test was used to check for statistically significant differences. A p-value of less than 0.05 was considered significant.

\section{Results and Discussion}

A total of 275 study participants answered the questionnaire, the majority (148 out of 275) $(53.9 \%)$ were Postgraduates and the remaining are CRRIs (46.1\%).

\section{Knowledge}

$90.9 \%$ (250 out of 275) had moderate knowledge. Postgraduates had better knowledge $(7.4 \%$ good) than the CRRIs (3.9\%) (Fig. 1A). The percentage of correct response of the two groups to the individual 
questions on hand hygiene knowledge is given in Table 1.

\section{Attitude}

$40.7 \%$ of the study population had moderate attitudes. Postgraduates had better attitude (46\% moderate) than CRRIs (34.6\%) (Fig. 1B). The percentage of correct response of the two groups to the individual questions on hand hygiene attitude is given in Table 2 .

\section{Practices}

$44 \%$ of the study population had moderate hand hygiene practice. Postgraduates had good practice $(25 \%)$ than CRRIs (15\%) (Fig. 1). The percentage of correct response of the two groups to the individual questions on hand hygiene practice is given in Table 3.

\section{Facilities}

$73.5 \%$ of the study population suggested improvement of the available facilities (Fig. 1D). The percentage of correct response of the two groups to the individual questions on facilities available for hand hygiene is given in Table 4.

Hand hygiene is one of the most effective means of preventing infection in developing countries. Knowledge of good hand hygiene practice and compliance in hand hygiene as per WHO guidelines is essential for lowering HAIs (WHO, 2002, 2009c). Hence, this cross sectional descriptive study was conducted to measure the knowledge, attitudes and practices of hand hygiene among Postgraduates and CRRIs in a tertiary care hospital.

The knowledge among the study group was found to be moderate $(90.9 \%)$. This finding is similar to study by Nair et al., (7) in which $72.5 \%$ of the participants had only moderate knowledge of hand hygiene practices. The
Postgraduates (7.4\%) had good knowledge on hand hygiene than CRRIs (3.9\%). Majority of the participants knew that hand hygiene should be performed before touching a patient $(96.7 \%)$ and after touching a patient $(98.5 \%)$. $99 \%$ had wrongly responded to the question the frequent source of germs responsible for HAI. Majority of the participants knew that hand rubbing is more rapid $(67.6 \%)$ and not more effective against germs than hand washing $(75 \%)$ but $77 \%$ of the study population responded that alcohol hand rub causes skin dryness. Only $2.5 \%$ knew the minimal time needed for alcohol based hand rub to kill most germs in the hands. Postgraduates had better knowledge on the questions asked about the factors associated with likelihood of colonization of hands with harmful germs than the CRRIs. This result of knowledge on hand hygiene in our study recommends the need for training program on hand hygiene to be imparted to both groups particularly CRRIs before they join the internship.

In our study we found that $40.7 \%$ of the study population had moderate attitude. Postgraduates had better positive attitude than the CRRIs. Similar finding have been reported in study done by Maheswari et al., (8). The compliance for hand hygiene was better among Postgraduates who adhere to correct hand hygiene practices at all times $(73 \%)$, feel frustrated when others omit hand hygiene $(47.3 \%)$ and feel guilty if they omit hand hygiene $(72.3 \%)$ which is similar to study conducted by Ariyaratne et al., (6). $40 \%$ of the study population reported that wearing gloves reduce the need for hand hygiene and $63 \%$ of the participants had the attitude that adhering to hand hygiene is not easy in the current setting which should be addressed during the training program.

In our study $20.4 \%$ of the participants had good practices in hand hygiene. $25 \%$ of postgraduates had good hand hygiene 
practices whereas $15 \%$ of CRRIs had good practices. $45.5 \%$ reported that the frequency of hand hygiene makes it difficult for them to carry out as often as necessary and $47 \%$ reported that it is difficult for them to attend hand hygiene courses due to time pressure. $83.8 \%$ of postgraduates felt that hand hygiene is an essential part of their role. $60.1 \%$ of postgraduates and $40.9 \%$ of CRRIs reported that infection promotion notice boards remind them to do hand hygiene. Infection prevention team had more positive influence on postgraduates than CRRIs. This shows that IPC team has a major role in improving the hand hygiene practices among HCP.

Our study reveals that postgraduates comply with the hand hygiene practices more than the CRRIs. The better hand washing practice among postgraduates may be due to their longer contact/ interaction time with the patients. Invasive and surgical procedures expose them to highly infectious agents, and so the need to wash their hands frequently is rather inevitable.

Noncompliance with guidelines and recommendations of hand hygiene are due to many factors. The factors may be due to lack of time, forgetfulness, lack of adequate facilities, lack of institutional commitment, lack of motivation, and skin irritation to hand hygiene products $(4,9)$. Considering these factors, a good strategy is to be implemented like multifaceted behavioral intervention program to educate, motivate and make a change in the system (10).

$73.5 \%$ of the participants suggested improvement of available facilities. $70 \%$ are not satisfied with the infection prevention notices. $88 \%$ reported non-availability of paper/clothes for drying hands. $73 \%$ of the participants are not satisfied with the training programs on hand hygiene. Similar findings were also reported in the study conducted in Ghana. (11). These findings corroborate the submission by the World Health Organization on the appalling state of water, sanitation and hygiene (WASH) services in health care facilities in low- and middle-income countries (12), and they re-emphasize the need for governments and other stakeholders to make provision of adequate water and materials for sanitation and hygiene in the health care facilities a top priority. Therefore we need to address this issue and improve the available facilities as per WHO norms.

Imparting training and behavioral change to the students who join the medical college and make hand hygiene and infection prevention and control to be a part of curriculum throughout the course like inclusion of regular theoretical education and practical demonstrations on hand hygiene from early on in the curriculum 13, using germ simulation to illustrate the transmission of bacteria 14, hands-on training 15, assessment tools like OSCE checklists as student learning is highly focused by formative and summative assessments16.Scheithauer et al., (17) conducted an observational study in Germany to evaluate the influence of teaching and monitoring on hand hygiene compliance and proposed implementation of regular education and practical training on hand hygiene from early on in the medical studies curriculum. Multiple methods have been suggested to improve awareness and compliance among students, as positive changes in their hand hygiene behavior will translate in improved compliance when they join the health care profession and act as mentors for future students (18).

The aim of our study is to provide useful insights into the prevailing practices of hand hygiene and major barriers to proper hand hygiene practices. A follow up study is planned to see the outcome of our changed strategies. 
Table.1

\begin{tabular}{|c|c|c|c|c|c|c|}
\hline \multirow[b]{2}{*}{ K1 } & \multirow[b]{2}{*}{$\begin{array}{l}\text { Which of the following is the main route of transmission of } \\
\text { potentially harmful germs between patients (Health care works } \\
\text { hands when not clean) }\end{array}$} & \multicolumn{2}{|c|}{ PG(n=148) } & \multicolumn{2}{|c|}{ CRRI(n=127) } & \multirow{2}{*}{$\begin{array}{l}\text { P-value } \\
0.000\end{array}$} \\
\hline & & 44 & $29.7 \%$ & 9 & $7.1 \%$ & \\
\hline \multirow[t]{2}{*}{ K2 } & $\begin{array}{l}\text { What is the most frequent source of germ responsible for health } \\
\text { care associated infections? (Germs already present on or within the } \\
\text { patient) }\end{array}$ & 3 & $2 \%$ & 0 & $0 \%$ & 0.000 \\
\hline & $\begin{array}{l}\text { Which of the following hand hygiene actions that prevent } \\
\text { transmission of germs to the patient? }\end{array}$ & & & & & \\
\hline K3 & Before touching a patient(yes) & 140 & $94.6 \%$ & 126 & $99.2 \%$ & NS \\
\hline K4 & Immediately after risk of body fluid exposure(yes) & 138 & $93.2 \%$ & 125 & $98.4 \%$ & 0.029 \\
\hline K5 & After exposure to immediate surroundings of a patient(no) & 25 & $16.9 \%$ & 19 & $15 \%$ & NS \\
\hline \multirow[t]{2}{*}{ K6 } & Immediately before a clean/aseptic procedure(yes) & 141 & $95.3 \%$ & 123 & $96.9 \%$ & NS \\
\hline & $\begin{array}{l}\text { Which of the following hand hygiene actions prevents } \\
\text { transmission of germs to the health care worker? }\end{array}$ & & & & & \\
\hline K7 & After touching a patient(yes) & 145 & $98 \%$ & 126 & $99.2 \%$ & NS \\
\hline K8 & Immediately after risk of body fluid exposure(yes) & 144 & $97.3 \%$ & 124 & $97.6 \%$ & NS \\
\hline K9 & Immediately before a clean/aseptic procedure(no) & 20 & $13.5 \%$ & 6 & $4.7 \%$ & 0.012 \\
\hline \multirow[t]{2}{*}{ K10 } & After exposure to immediate surroundings of a patient(yes) & 129 & $87.2 \%$ & 105 & $82.7 \%$ & NS \\
\hline & $\begin{array}{l}\text { Which of the following statement on alcohol based rub and } \\
\text { hand washing with soap and water are true or false? }\end{array}$ & & & & & \\
\hline K11 & $\begin{array}{l}\text { Hand rubbing is more rapid for hand cleansing than hand } \\
\text { washing(true) }\end{array}$ & 95 & $64.2 \%$ & 91 & $71.7 \%$ & 0.046 \\
\hline K12 & Hand rubbing causes skin dryness more than hand washing (false) & 29 & $19.6 \%$ & 34 & $26.8 \%$ & NS \\
\hline K13 & $\begin{array}{l}\text { Hand rubbing is more effective against germs than hand } \\
\text { washing(false) }\end{array}$ & 114 & $77 \%$ & 92 & $72.4 \%$ & NS \\
\hline K14 & $\begin{array}{l}\text { Hand washing and hand rubbing are recommended to be performed } \\
\text { in sequence(false) }\end{array}$ & 79 & $53.4 \%$ & 66 & $52 \%$ & 0.000 \\
\hline \multirow[t]{2}{*}{ K15 } & $\begin{array}{l}\text { What is the minimal time needed for alcohol based hand rub to kill } \\
\text { most germs on your hands?(20seconds) }\end{array}$ & 7 & $4.7 \%$ & 0 & $0 \%$ & 0.000 \\
\hline & $\begin{array}{l}\text { Which type of hand hygiene method is required in the following } \\
\text { situations?(hand rubbing or hand washing) }\end{array}$ & & & & & \\
\hline K16 & Before palpation of the abdomen(rubbing) & 99 & $67.3 \%$ & 78 & $61.4 \%$ & 0.007 \\
\hline K17 & Before giving an injection(rubbing) & 81 & $54.7 \%$ & 84 & $66.1 \%$ & 0.000 \\
\hline K18 & After emptying a bed pan(washing) & 132 & $89.2 \%$ & 101 & $79.5 \%$ & 0.033 \\
\hline K19 & After removing examination gloves(rubbing/washing) & 143 & $96.6 \%$ & 126 & $99.2 \%$ & NS \\
\hline K20 & After making a patients bed(rubbing) & 49 & $33.1 \%$ & 40 & $31.5 \%$ & 0.018 \\
\hline \multirow[t]{2}{*}{ K21 } & After visible exposure to blood and body fluids(washing) & 127 & $85.8 \%$ & 98 & $77.2 \%$ & NS \\
\hline & $\begin{array}{l}\text { Which of the following should be avoided as associated with } \\
\text { increased likelihood of colonization of hands with harmful } \\
\text { germs? }\end{array}$ & & & & & \\
\hline K22 & Wearing jewel(yes) & 125 & $84.5 \%$ & 78 & $61.4 \%$ & 0.000 \\
\hline K23 & Damaged skin (yes) & 141 & $95.3 \%$ & 123 & $96.9 \%$ & NS \\
\hline K24 & After fingernails (yes) & 144 & $97.3 \%$ & 123 & $96.9 \%$ & NS \\
\hline K25 & Regular use of hand cream(no) & 103 & $69.6 \%$ & 78 & $61.4 \%$ & 0.002 \\
\hline
\end{tabular}

Correct answer to each response is given within brackets. Significance calculated using Pearson chi-square test ${ }^{*} \mathrm{p}<0.05$ (Significant), ${ }^{* *} \mathrm{p}<0.001$ (highly significant), NS (Not significant) 


\section{Table.2}

\begin{tabular}{|c|c|c|c|c|c|c|}
\hline & & PG(r & & & $(n=127$ & P-value \\
\hline A1 & I adhere to correct hand hygiene practices at all times & 108 & $73 \%$ & 80 & $63 \%$ & 0.000 \\
\hline A2 & I have sufficient knowledge about hand hygiene & 116 & $78.4 \%$ & 83 & $\begin{array}{l}65.4 \\
\%\end{array}$ & 0.000 \\
\hline $\mathbf{A 3}$ & $\begin{array}{l}\text { Sometime I have more important things to do than hand } \\
\text { hygiene }\end{array}$ & 47 & $31.8 \%$ & 36 & $\begin{array}{l}28.3 \\
\%\end{array}$ & 0.005 \\
\hline A4 & $\begin{array}{l}\text { Emergencies and other priorities make hand hygiene more } \\
\text { difficult at times }\end{array}$ & 79 & $53.4 \%$ & 93 & $\begin{array}{l}73.2 \\
\%\end{array}$ & 0.003 \\
\hline A5 & Wearing gloves reduce the need for hand hygiene & 49 & $33.1 \%$ & 63 & $\begin{array}{l}49.6 \\
\%\end{array}$ & 0.003 \\
\hline A6 & I feel frustrated when others omit hand hygiene & 70 & $47.3 \%$ & 36 & $\begin{array}{l}28.3 \\
\%\end{array}$ & 0.000 \\
\hline A7 & I am reluctant to ask others to engage in hand hygiene & 38 & $25.7 \%$ & 27 & $\begin{array}{l}21.3 \\
\%\end{array}$ & 0.000 \\
\hline A8 & $\begin{array}{l}\text { Newly qualified staff has not been properly instructed in } \\
\text { hand hygiene in their training }\end{array}$ & 55 & $37.2 \%$ & 26 & $\begin{array}{l}20.5 \\
\%\end{array}$ & 0.010 \\
\hline A9 & I feel guilty if omit hand hygiene & 107 & $72.3 \%$ & 77 & $\begin{array}{l}60.6 \\
\%\end{array}$ & 0.000 \\
\hline $\begin{array}{l}\mathbf{A 1} \\
\mathbf{0}\end{array}$ & $\begin{array}{l}\text { Adhering to hand hygiene practices is easy in the current } \\
\text { setting }\end{array}$ & 68 & $45.9 \%$ & 34 & $\begin{array}{l}26.8 \\
\%\end{array}$ & 0.000 \\
\hline
\end{tabular}

Correct answer to each response is given within brackets. Significance calculated using Pearson chi-square test ${ }^{*} \mathrm{p}<0.05$ (Significant), $*$ p $<0.001$ (highly significant), NS (Not significant)

Table.3

\begin{tabular}{|l|l|l|l|l|l|l|}
\hline & & \multicolumn{2}{|l|}{ PG(n=148) } & \multicolumn{2}{l|}{ CRRI(n=127 } & P-value \\
\hline $\mathbf{P}$ & Sometimes I miss out hand hygiene simply because I forget it & 55 & $37.2 \%$ & 43 & $\begin{array}{l}33.9 \\
\mathbf{1}\end{array}$ & 0.013 \\
\hline $\mathbf{P}$ & Hand hygiene is an essential part of my role & 124 & $83.8 \%$ & 99 & $78 \%$ & 0.000 \\
\hline $\mathbf{2}$ & $\begin{array}{l}\text { The frequency of hand hygiene required makes it difficult for } \\
\mathbf{3}\end{array}$ & 66 & $44.6 \%$ & 59 & $\begin{array}{l}46.5 \\
\%\end{array}$ & $\mathrm{NS}$ \\
\hline $\begin{array}{l}\mathbf{P} \\
\mathbf{4}\end{array}$ & $\begin{array}{l}\text { Infection prevention team have a positive influence on my } \\
\text { hand hygiene }\end{array}$ & 84 & $56.8 \%$ & 43 & $\begin{array}{l}33.9 \\
\%\end{array}$ & 0.000 \\
\hline $\mathbf{P}$ & $\begin{array}{l}\text { Infection prevention notice boards remind me to do hand } \\
\text { hygiene }\end{array}$ & 89 & $60.1 \%$ & 52 & $\begin{array}{l}40.9 \\
\%\end{array}$ & 0.001 \\
\hline $\begin{array}{l}\mathbf{P} \\
\mathbf{6}\end{array}$ & $\begin{array}{l}\text { It is difficult for me to attend hand hygiene courses due to } \\
\text { time pressure }\end{array}$ & 64 & $43.2 \%$ & 66 & $52 \%$ & NS \\
\hline
\end{tabular}

Correct answer to each response is given within brackets. Significance calculated using Pearson chi-square test ${ }^{*} \mathrm{p}<0.05$ (Significant), $* * \mathrm{p}<0.001$ (highly significant), NS (Not significant) 
Table.4

\begin{tabular}{|c|c|c|c|c|c|c|}
\hline \multirow[b]{2}{*}{ F1 } & \multirow[b]{2}{*}{$\begin{array}{l}\text { Are you satisfied with the facilities available for hand } \\
\text { hygiene }\end{array}$} & \multicolumn{2}{|c|}{ PG(n=148) } & \multicolumn{2}{|c|}{ CRRI(n=127) } & \multirow{2}{*}{$\begin{array}{l}\text { P-value } \\
0.000\end{array}$} \\
\hline & & 37 & $25 \%$ & 21 & $16.5 \%$ & \\
\hline & Satisfaction with availability of & & & & & \\
\hline F2 & Infection prevention notices & 42 & $28.4 \%$ & 41 & $32.3 \%$ & 0.000 \\
\hline F3 & Soap /Antiseptic and water for hand washing & 49 & $33.1 \%$ & 35 & $27.6 \%$ & 0.000 \\
\hline F4 & Alcohol rub & 40 & $27 \%$ & 40 & $31.5 \%$ & 0.003 \\
\hline F5 & Paper /clothes for drying hands & 14 & $9.5 \%$ & 18 & $14.2 \%$ & 0.000 \\
\hline F6 & Availability of gloves & 69 & $46.6 \%$ & 48 & $37.8 \%$ & 0.000 \\
\hline F7 & Number of sinks with running water & 56 & $37.8 \%$ & 33 & $26 \%$ & 0.000 \\
\hline F8 & Training programs on hand hygiene conducted by the hospital & 34 & $23 \%$ & 40 & $31.5 \%$ & 0.000 \\
\hline
\end{tabular}

Correct answer to each response is given within brackets. Significance calculated using Pearson chi-square test $* \mathrm{p}<0.05$ (Significant), $* * \mathrm{p}<0.001$ (highly significant), NS (Not significant)

Fig.1 Comparison of knowledge, attitudes, practices and satisfaction with facilities among postgraduates and CRRIs is represented

A

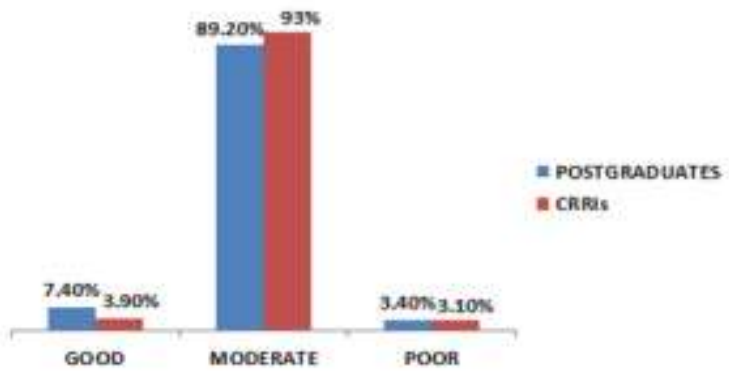

$\mathbf{C}$

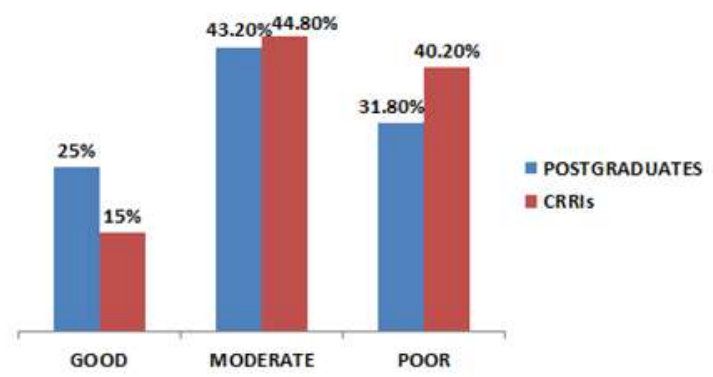

In conclusion, improved hand hygiene has been shown to reduce HCAI spread by $40 \%$ and full compliance can reduce the risk of
B

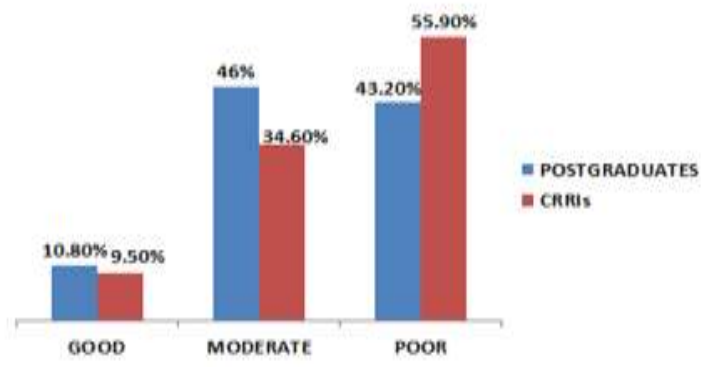

D

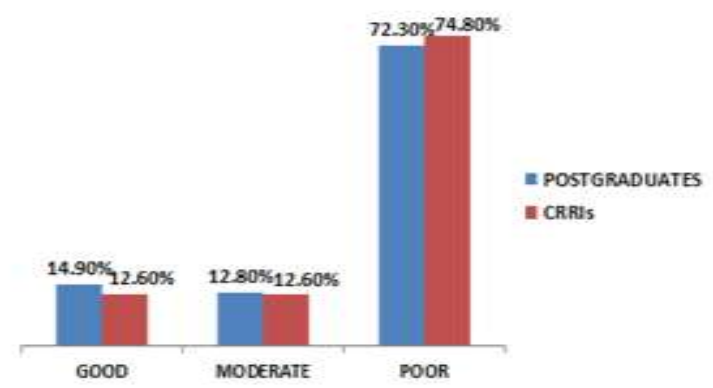

acquiring methicillin-resistant Staphylococcus aureus (MRSA), a common cause of severe infections in HCFs, by 24\%.(19).In our study, 
we have observed that level of knowledge regarding the hand hygiene is moderate in the study population. There is a need for training and orientation programs and to include hand hygiene practices in the academic curriculum of medical students

The attitudes, practices and satisfaction of available facilities of the study population were unsatisfactory. Emphasizing the importance of hand hygiene and encouraging the study population to follow good hand hygiene practices by displaying infection prevention notices, easy access to hand hygiene facilities and active involvement will be useful in increasing hand hygiene compliance. We recommend monitoring of hand hygiene compliance under strict supervision and hand hygiene audit to be done in day-to-day hospital activities.

Hand hygiene awareness can be improved to a great extent by conducting awareness programs frequently by the Infection control committee in the Medical College \& Hospital campus.

\section{Limitations of our Study}

The main limitation in this study is deliberate misinformation by the study subjects regarding their hand hygiene practices, as the data obtained was based on self-reported practices instead of direct observation.

\section{Recommendations from our study}

To conduct hand washing training programs and to implement multifaceted interventional behavioral hand hygiene program for improving the compliance

Constant motivation and empowering students to internalize and comply with $\mathrm{HH}$ practices

Continuous monitoring and evaluation of the compliance by hand hygiene audit with recommended instructions.

To develop protocols, programs and administration activities regarding hand hygiene facilities in the hospital.

Encourage future researches on hand hygiene practices in health facilities.

\section{References}

1. WHO: The Burden of health careassociated infection worldwide. A Summary. http://www.who.int/gpsc/ country_work/summary_20100430_en. pdf

2. Allegranzi B, Pittet D. 2009. Role of hand hygiene in healthcare associated infection prevention. J Hosp Infect. 73:305-15

3. Larson E. 1988. A causelink between handwashing and risk of infection? Examination of the evidence. infect Control Hosp. Epidemiol., 9:28-36.

4. D. Pittet, S. et al., 2000. Effectiveness of a hospital-wide programme to improve compliance with hand hygiene. The Lancet; 356: 1307-1312.

5. World Health Organization. 2009. WHO Guidelines on Hand Hygiene in Health Care: First global safety challenge: clean care is safe care. Geneva: WHO http://whqlibdoc.who.int/publications I $2009 / 9789241597$ 906_eng. pdf Accessed June 1"8, 2010.

6. Ariyaratne MHJD et al., 2013. Knowledge, attitudes and practices of hand hygiene among final year medical and nursing students at the University of Sri Jayewardenepura. Sri Lankan Journal of Infectious Diseases. 3(1): 15-25.

7. Nair SS et al., 2016. Knowledge, Attitude, and Practice of Hand Hygiene among Medical and Nursing Students at a Tertiary Health Care Centre in Raichur, India. ISRN Prev Med., 6: 608927.

8. Maheshwari V, et al., 2014. A Study to Assess Knowledge and Attitude 
Regarding Hand Hygiene amongst Residents and Nursing Staff in a Tertiary Health Care Setting of Bhopal City. Journal of Clinical and Diagnostic Research. 8(8).

9. Boyce JM, Pittet D; Healthcare Infection Control Practices Advisory Committee; HICPAC/SHEA/APIC/IDSA Hand Hygiene Task Force: Guideline for Hand Hygiene in Health- Care Settings. Recommendations of the Healthcare Infection Control Practices Advisory Committee and the HICPAC/SHEA/APIC/IDSA Hand Hygiene Task Force. Society for Healthcare Epidemiology of America/Association for Professionals in Infection Control/Infectious Diseases Society of America. MMWR Recomm Rep. 2002, 51:1-45. 10.1067/mic.2002. 13039

10. Kretzer EK, Larson EL. 1998. Behavioral interventions to improve infection control practices. Am J Infect Control. 26:245-53.

11. AmissahI et al., 2006. A study to assess hand hygiene knowledge and practice among health care workers in a teaching hospital in Ghana. Intl J Sci Res 5(8):301-307.

12. World Health Organization / United Nations' Children's Fund. Water, sanitation and hygiene in healthcare facilities: status in low- and middle income countries and the way forward. Geneva, Switzerland: WHO/UNICEF; 2017.
Available:htpps://www.who.int/water_s anit ation_health/publications/washhealthcare- facilities/en/

13. P. Mathur, 2011 "Hand hygiene: back to the basics of infection control," Indian Journal of Medical Research, vol. 134, no. 11, pp. 611-620.

14. M. K. Mittal, et al., 2011. "Germ simulation: a novel approach for raising medical students awareness toward asepsis," Simulation in Healthcare, vol. 6, no. 2, pp. 65-70.

15. D. Fisher, et al., 2010, "Teaching hand hygiene to medical students using a hands-on approach," Journal of Hospital Infection, vol. 76, no. 1, pp. 86-87.

16. A. Feather, et al., 2000. "Now please wash your hands': the handwashing behaviour of final MBBS candidates," Journal of Hospital Infection, vol. 45, no. 1, pp. 62-64.

17. S. Scheithauer, et al., 2012 "Hand hygiene in medical students: performance, education and knowledge," International Journal of Hygiene and Environmental Health, vol. 215, no. 5, pp. 536-539.

18. S. Kelc'ikova, et al., 2012. "Effectiveness of hand hygiene education in basic nursing school curricula," Public Health Nursing, vol. 29, no. 2, pp. 152-159.

19. Evidence of hand hygiene to reduce transmission and infections by multidrug resistant organisms in health-care settings. World Health Organization. http://www.who.int/gpsc/5may/MDRO_ literature-review.pdf

\section{How to cite this article:}

Ravichandran, B., K.V. Leela, Thyagarajan Ravinder, M. Kavitha, S. Hemalatha and Rajasekaran, C. 2019. Hand Hygiene Knowledge, Attitude and Practices among Postgraduates and CRRIs in a Tertiary Care Hospital, Chennai, India. Int.J.Curr.Microbiol.App.Sci. 8(01): 1404-1412. doi: https://doi.org/10.20546/ijcmas.2019.801.149 